Acta Protozool. (2019) 58: 89-92

www.ejournals.eu/Acta-Protozoologica

doi:10.4467/16890027AP.19.008.11417

PROTOZOOLOGICA

Short communication

\title{
In vitro Trypanosoma cruzi Growth Inhibition by Extremely Low-frequency Electromagnetic Fields
}

\author{
J. Antonio Heredia-Rojasa, Abraham O. Rodríguez-De la Fuentea, Ricardo Gomez-Flores ${ }^{a}$, Merary \\ Alvarez-Rodríguez ${ }^{\mathrm{a}}$, Zinnia J. Molina-Garzab, M. Beltcheva ${ }^{\mathrm{c}}$, Omar Heredia-Rodrígueza ${ }^{\mathrm{a}}$, Lucio \\ Galaviz-Silva ${ }^{b}$ \\ ${ }^{a}$ Universidad Autónoma de Nuevo León, Facultad de Ciencias Biológicas, Departamento de Ciencias Exactas y Desarrollo Humano, \\ San Nicolás de los Garza, Nuevo León, México

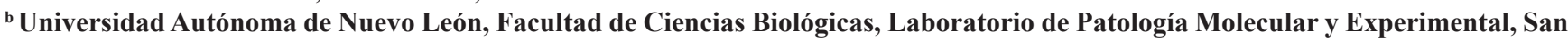 \\ Nicolás de los Garza, Nuevo León, México \\ ${ }^{c}$ Institute of Biodiversity and Ecosystem Research, Bulgarian Academy of Sciences, Sofia, Bulgaria
}

\begin{abstract}
The influence of extremely low-frequency electromagnetic fields (ELF-EMFs) on microorganisms has been a subject of experimental investigations with promising results. In the present study, it was demonstrated that $2.0 \mathrm{mT} 60 \mathrm{~Hz}$ ELF-EMFs inhibited Trypanosoma cruzi epimastigotes growth. In addition, no synergistic or antagonistic parasite growth and viability effects were observed after cultures were co-exposed to magnetic fields and Nifurtimox, a well-known anti-trypanosome drug. Moreover, the current study represents the first report regarding direct magnetic fields effects on Trypanosomas.
\end{abstract}

Key words: Trypanosoma cruzi, antiprotozoal activity, 60-Hz sinusoidal magnetic fields, anti-trypanosome

\section{INTRODUCTION}

Trypanosoma cruzi, the etiologic agent of Chagas disease, considered a public health problem in Latin America, is a kinetoplastid parasite that has been reported as a highly resistant organism to energetic radiation (Regis-da-Silva et al. 2006; Vieira et al. 2014). Efforts

\footnotetext{
Address for correspondence: Zinnia J. Molina Garza, Universidad Autónoma de Nuevo León, Facultad de Ciencias Biológicas, Unidad B, Laboratorio de Patología Molecular y Experimental, Ave. Universidad S/N, Cd. Universitaria, San Nicolás de los Garza, Nuevo León. CP.66455. México Phone +528183762813; E-mail: zinniajudithmolina@gmail.com
}

have been made to control species of this hemoflagellate protozoan parasite with drugs (Bern 2011) and plant extract agents (Molina-Garza et al. 2014). In regard to parasite growth inhibition using unconventional procedures, the effect of $60 \mathrm{~Hz}$ magnetic fields at 1.5 and $2.0 \mathrm{mT}$ on Entamoeba invadens trophozoites growth inhibition and encystation in-vitro has been previously demonstrated (Rodríguez-De la Fuente et al. 2008). Furthermore, it was reported that by transferring electronic-metronidazole information to water samples, Entamoeba histolytica and Trichomonas vaginalis growth was significantly inhibited (Heredia-Rojas et al. 2011).

There are no recent reports relating ELF-EMFs and Trypanosomes, however, about four decades ago, 
French researchers reported anti-trypanosome effect of magnetic fields on rabbits (Pautrizel et al. 1970) and mice (Pautrizel et al. 1975); they observed that the control of the infection was not due to a direct action of the radiation on trypanosomes, but to a very strong stimulation of the immune system. Moreover, Bellosi (1983) found no-effect of a static magnetic field of 400 $\mathrm{mT}$ on mice infected with T. equiperdum; in addition, there was no difference between the length of survival of the animals exposed to magnetic fields, as compared with non-exposed mice. The present study was undertaken to evaluate the potential of ELF-EMFs to inhibit Trypanosoma cruzi epimastigote growth.

\section{MATERIALS AND METHODS}

Bioassays were developed using T. cruzi CL Brener strain cultured at $27^{\circ} \mathrm{C}$ in liver infusion triptose medium, supplemented with $10 \%$ fetal bovine serum and harvested during the exponential growth phase (cell density of about $4 \times 10^{6}$ epimastigotes $/ \mathrm{mL}$ ) (Molina-Garza et al. 2014). Experiments were performed in triplicate in 96-well microtiter plates containing $200 \mu \mathrm{L} /$ well of the parasite suspension at a density of $1.0 \times 10^{6}$ epimastigotes $/ \mathrm{mL}$. The following treatment and control groups were used: $(a)$ cells exposed to ELF-EMFs at $60 \mathrm{~Hz}$ and $2.0 \mathrm{mT},(b)$ untreated cells, used as controls, $(c)$ cells treated with Nifurtimox at 0.066 and $0.132 \mu \mathrm{M} / \mathrm{mL}$ (Bern 2011), used as positive controls, and $(d)$ cells co-exposed to ELF-EMFs and Nifurtimox. Nine replicate determinations of three independent experiments, providing a total of 27 cultures analyzed per group were performed. When cultures reached the end of logarithmic phase, they were exposed to ELF-EMFs for $24 \mathrm{~h}$. Magnetic field exposure was developed by using a standardized device, as we previously reported (Rodríguez-De la Fuente et al. 2008). In summary, this device comprised a coil that was built by winding 552 turns of $1.3 \mathrm{~mm}$ diameter enamel insulated copper wire to form a cylindrical solenoid with a radius of $13.5 \mathrm{~cm}$ and a length of $71 \mathrm{~cm}$. The solenoid was connected to a step-down transformer and to a variable transformer that was plugged in to a $110 \mathrm{~V}$ AC source. The samples were allocated in pre-determined zones where the magnetic field was homogeneous. The magnetic flux density (rms) was evaluated by an axial Hall-effect probe (Bell FW 6010 Gaussmeter, Orlando, Fl, USA), coupling an oscilloscope (BK-Precision model 2120) to monitor the resulting field; a $2.0 \mathrm{mT} 60 \mathrm{~Hz}$ alternating sinusoidal electromagnetic field was then generated, obtaining a nearly pure $60 \mathrm{~Hz}$ field frequency $(<3 \%$ total harmonic distortion). On the other hand, to test the combination of ELF-EMF treatment and Nifurtimox (Sigma-Aldrich, St. Louis, MO, USA) on epimastigote growth and viability, a co-exposure experiment was included. Nifurtimox solutions at 0.066 and $0.132 \mu \mathrm{M} / \mathrm{mL}$ were prepared in $1 \%$ dimethyl sulfoxide (DMSO). Cultures were co-exposed at the same time for $24 \mathrm{~h}$. For determining the cytotoxic effects, epimastigotes density was blindly evaluated and counted three times in a Neubauer chamber; parasite viability was determined by a colorimetric technique using the tetrazolium salt 3-(4,5-dimethyl-2-thiazolyl)-2,5-diphe-
nyl-2H-tetrazolium bromide (MTT, Sigma-Aldrich) (Molina-Garza et al. 2014). Statistical differences among groups were calculated by using analysis of variance for normal distributions, followed by a parametric Tukey test to establish individual differences $(p<0.01)$.

\section{RESULTS AND DISCUSSION}

A significant $(p<0.01)$ decrease in epimastigote growth was observed in cultures treated with magnetic fields (64\% growth inhibition), as compared with controls (Fig. 1). Moreover, magnetic field-treated cultures showed significant $(p<0.01)$ lower cell counts when compared with $0.066 \mu \mathrm{M} / \mathrm{mL}$ of Nifurtimox $(25 \%$ growth inhibition, as compared with control), but higher counts when compared with $0.132 \mu \mathrm{M} / \mathrm{mL}$ Nifurtimox $(87 \%$ growth inhibition, as compared with control) (Fig. 1). On the other hand, cultures co-exposed to ELF-EMFs and Nifurtimox showed no significant differences when compared with cultures treated with Nifurtimox alone. Cultures treated with Nifurtimox showed lower cell density as compared with negative controls, as expected $(p<0.01)$. In regard to cell viability, magnetic field exposure caused significant $(p<0.01)$ reduction of epimastigote cultures viability, as compared with untreated control; in addition, no synergistic or antagonistic effects were observed after co-exposing cultures to ELF-EMFs and Nifurtimox, as compared with Nifurtimox alone (Fig. 2). As expected, cultures treated with Nifurtimox showed significant $(p<0.01)$ lower percentages of viability, as compared with controls (Fig. 2).

These results agreed with our previous report on Entamoeba invadens trophozoites; growth inhibition after exposing them to $2.0 \mathrm{mT}$ (Rodríguez-De la Fuente et al. 2008). Additionally, a diminution of Entamoeba histolytica and Entamoeba dispar trophozoite growth was observed in axenic cultures after exposure to $900 \mathrm{MHz}$ electromagnetic fields (Aksoy et al. 2006). To date, there are no reports involving ELF-EMFs effects on T. cruzi. However, related studies have been reported in protozoans. Amaroli et al. (2006) observed a decreased cellular fission rate and a delay in the early phase of the differentiation cycle in single-cell amoebae of Dictyostelium discoideum exposed to $50 \mathrm{~Hz}$, ELF-EMFs at $200 \mu \mathrm{T}$. Our findings suggested that lower cell counts were related to ELF-EMF exposure, which may involve alterations in cell cycle progression. In addition, it has been suggested by others that electroporation or electro-permeabilization induced by electric and 50-60 


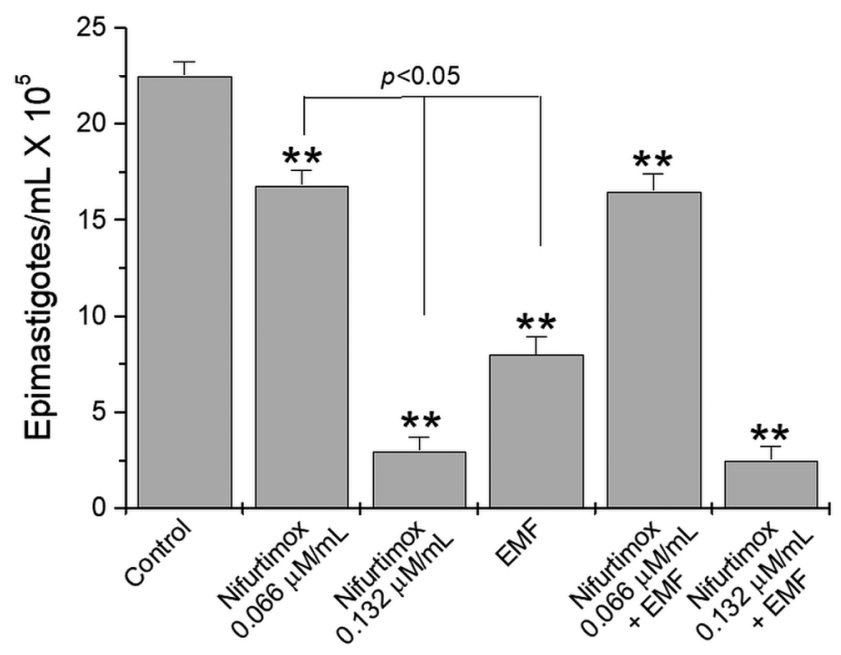

Fig. 1. Effect of $60 \mathrm{~Hz}$ sinusoidal magnetic fields at $2.0 \mathrm{mT}$ and $24 \mathrm{~h}$ exposure on cell growth of $T$. cruzi epimastigote cultures. Bars represent arithmetical grouped means \pm standard deviations.

$\mathrm{Hz}$ oscillating magnetic fields destroys cell membranes and acts as an antimicrobial procedure (Zimmermann 1998).

Exposure to ELF-EMFs results in a number of important biological changes. With regard to the present study, one possibility is that the parasites reacted to magnetic fields in a similar way to that observed under cellular stress. This is supported by the observation that there is an increase in heat shock gene transcripts (e.g., hsp70) following exposure to ELF-EMFs, where no increases in temperature were measured or expected due to the design of the exposure system with similar characteristics as the one used in the present study. Evidence for this possibility was proposed by Goodman and Blank (1998), and later by our research group after exposing human cells to $60 \mathrm{~Hz}$ sinusoidal magnetic fields at 8 and $80 \mu \mathrm{T}$ (Heredia-Rojas et al. 2010).

In addition, significant reduction in cell viability was observed after $T$. cruzi cultures were exposed to magnetic fields, suggesting a direct anti-parasite effect. In the existing literature, there are no reports indicating a direct effect of magnetic fields on $T$. cruzi viability. Furthermore, our results showed no synergistic or antagonistic growth and viability effects of ELF-EMFs exposure and Nifurtimox combination. There are reports attempting to investigate synergistic or antagonistic effects by co-exposure conditions for a variety of radiations, chemicals, and cytological endpoints.

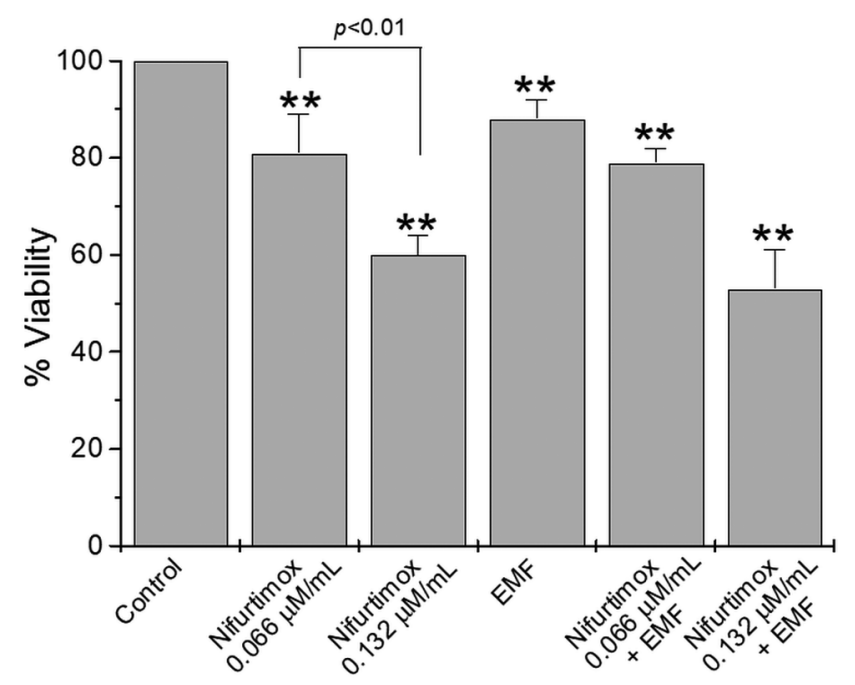

Fig. 2. Effect of $60 \mathrm{~Hz}$ sinusoidal magnetic fields at $2.0 \mathrm{mT}$ and $24 \mathrm{~h}$ exposure on cell viability of T. cruzi epimastigote cultures. Bars represent arithmetical grouped means \pm standard deviations.

We have previously observed an antagonistic effect between magnetic field exposure and mitomycin-C, a well-known cytotoxic agent, on human lymphocytes proliferation (Heredia-Rojas et al. 2001), and for chromosomal aberrations and sperm morphology in germ cells of mice (Heredia-Rojas et al. 2004). In this concern, Yoon et al. (2014) found that a $2.0 \mathrm{mT}$ ELF-EMF exposure potentiated the expression of $\mathrm{y}-\mathrm{H} 2 \mathrm{AX}$ and $\mathrm{y}-\mathrm{H} 2 \mathrm{~A}$ foci production when combined with ionizing radiation, but not when combined with hydrogen peroxide in non-tumorigenic human cell lines.

In conclusion, the present study suggested that 60 $\mathrm{Hz}$ magnetic fields induced a significant decrease in T. cruzi epimastigotes growth and viability after 24 $\mathrm{h}$ exposure to $2.0 \mathrm{mT}$. However, with the results presented here, we are not supporting any therapeutic technique nor recommending electromagnetic approaches, rather we showed evidence for a significant and measurable biological effect induced by magnetic fields on T. cruzi.

\section{REFERENCES}

Aksoy U., Sahin S., Ozkoc S., Ergor G. (2006) The effect of electromagnetic waves on the growth of Entamoeba histolytica and Entamoeba dispar. Saudi Med. J. 26: 1388-1390

Amaroli A., Trielli F., Bianco B., Giordano S., Moggia E., Corrado M. U. (2006) Effects of a $50 \mathrm{~Hz}$ magnetic field on Dictyostelium discoideum (Protista). Bioelectromagnetics. 27: 528-534

Bellosi A. 1983. No-effect of a static uniform magnetic field on mouse trypanosomiasis. Radiat. Environ. Biophys. 22: 311-313 
Bern C. (2011) Antitrypanosomal Therapy for Chronic Chagas' Disease. N. Engl. J. Med. 364: 2527-2534

Goodman R., Blank M. (1998) Magnetic field stress induces expression of hsp70 (Mini-review). Cell Stress Chaperones. 3: 79-88

Heredia-Rojas J. A., Rodríguez-De la Fuente A. O., Velasco-Campos M. R., Leal-Garza C. H., Rodríguez-Flores L. E., De la FuenteCortéz B. (2001) Cytological effects of $60 \mathrm{~Hz}$ magnetic fields on human lymphocytes in vitro: sister chromatid exchanges, cell kinetics and mitotic rate. Bioelectromagnetics. 22: 145-149

Heredia-Rojas J. A., Caballero-Hernández D. E., Rodríguez-De la Fuente A. O., Ramos-Alfano G., Rodríguez-Flores L. E. (2004) Lack of alterations on meiotic chromosomes and morphological characteristics of male germ cells in mice exposed to a 60 $\mathrm{Hz}$ and $2.0 \mathrm{mT}$ magnetic field. Bioelectromagnetics. 25: 63-68

Heredia-Rojas J. A., Rodríguez-de la Fuente A. O., Alcocer-González J. M., Rodríguez-Flores L. E., Rodríguez-Padilla C., Santoyo-Stephano M. A., Castañeda-Garza E., Taméz-Guerra R. S. (2010) Effect of $60 \mathrm{~Hz}$ magnetic fields on the activation of hsp70 promoter in cultured INER-37 and RMA E7 cells. In Vitro Cell. Dev. Biol. Anim. 46: 758-63

Heredia-Rojas J. A., Torres-Flores A. C., Rodríguez-De la Fuente A. O., Mata-Cárdenas B. D., Rodríguez-Flores L. E., Barrón-González M. P., Torres-Pantoja A. C., Alcocer-González J. M. (2011) Entamoeba histolytica and Trichomonas vaginalis: Trophozoite growth inhibition by metronidazole electro-transferred water. Exp. Parasitol. 127: 80-83

Molina-Garza Z. J., Bazaldúa-Rodríguez A. F., Quintanilla-Licea R., Galaviz-Silva L. (2014) Anti-Trypanosoma cruzi activity of 10 medicinal plants used in northeast Mexico. Acta Trop. 136: 14-18

Pautrizel R., Prioré A., Berlureau F., Pautrizel A. N. (1970) Effect of magnetic fields combined with electromagnetic waves on ex- perimental trypanosomiasis of rabbit. C.R. Hebd. Seances Acad. Sci., Ser. D, Sci. Nat. D. 271: 877-880

Pautrizel R., Prioré A., Mattern P., Pautrizel A. N. (1975) Stimulation of the defenses of trypanosomic mice by a combination of magnetic field and electromagnetic wave radiation.C.R. Hebd. Seances Acad. Sci., Ser. D, Sci. Nat. 280: 1915-1918

Regis-da-Silva C. G., Freitas J. M., Passos-Silva D. G., Furtado C., Augusto-Pinto L., Pereira M. T., DaRocha W. D., Franco G. R., Macedo A. M., Hoffmann J. S., Cazaux C., Pena S. D., Teixeira S. M., Machado C. R. (2006) Characterization of the Trypanosoma cruzi Rad51 gene and its role in recombination events associated with the parasite resistance to ionizing radiation. Mol. Biochem. Parasitol. 149: 191-200

Rodríguez-De la Fuente A. O., Heredia-Rojas J. A., Mata-Cárdenas B. D., Vargas-Villarreal J., Rodríguez-Flores L. E., BalderasCandanosa I., Alcocer-González J. M. (2008) Entamoeba invadens: Influence of $60 \mathrm{~Hz}$ magnetic fields on growth and differentiation. Exp. Parasitol. 119: 202-206

Vieira H. G. S., Grynberg P., Bitar M., Pires SdF., Hilário H.O., Macedo A. M., Machado C. R., Monteiro de Andrade H., Franco G. R. (2014) Proteomic analysis of Trypanosoma cruzi response to ionizing radiation stress. Plos One 9: e97526

Yoon H. E., Lee J. S., Myung S. H., Lee Y. S. (2014) Increased y$\mathrm{H} 2 \mathrm{AX}$ by exposure to a $60-\mathrm{Hz}$ magnetic fields combined with ionizing radiation, but not hydrogen peroxide, in non-tumorigenic human cell lines. Int. J. Rad. Biol. 90: 291-298

Zimmermann U. (1998) Electric breakdown, electropermeabilization and electrofusion. Rev. Physiol. Biochem. Pharmacol. 105: $175-256$

Received on $8^{\text {th }}$ April, 2019; revised on $26^{\text {th }}$ September, 2019; accepted on $30^{\text {th }}$ September, 2019 